\title{
Modern Classification of Acute Kidney Injury
}

\author{
Nattachai Srisawat ${ }^{a}$ Eric E.A. Hoste ${ }^{a, b}$ John A. Kellum ${ }^{a}$ \\ aThe CRISMA (Clinical Research, Investigation, and Systems Modeling of Acute Illness) Laboratory, \\ Department of Critical Care Medicine, University of Pittsburgh School of Medicine, Pittsburgh, Pa., USA; \\ bIntensive Care Unit, Ghent University Hospital, Ghent, Belgium
}

\section{Key Words}

Acute kidney injury · RIFLE criteria • AKIN staging •

Severity $\cdot$ Mortality

\begin{abstract}
Acute kidney injury (AKI) is a common clinical syndrome defined as a sudden onset of reduced kidney function manifested by increased serum creatinine or a reduction in urine output. This clinical syndrome has been called by 25 different names and at least 35 definitions. As a result of this deficiency of standardized definition, reported incidences of AKI in the ICU range from 1 to $25 \%$ with mortality rates between 15 and $60 \%$. This lack of a uniform definition not only leads to the conflicting reports in the literature but is also a major obstacle for research in the field. The recent consensus definition which was proposed by the ADQI group and expanded by AKIN has brought the RIFLE criteria and staging into position as the standard definition and diagnosis of this syndrome. The RIFLE criteria have been extensively validated in more than 550,000 patients worldwide.
\end{abstract}

Copyright $\odot 2010$ S. Karger AG, Basel

\section{From Ischuria Renalis to Acute Kidney Injury}

Before the 18th century, there were only a few references to acute kidney disease (AKI). In ancient times, Galen clearly defined the differential diagnosis of suppression of urine output (ischuria) based on the presence or absence of a distended bladder on bedside physical examination [1]. In 1796, Batista Morgagni, the famous anatomist and pathologist, first introduced the terminology where ischuria was based on organ pathology: ischuria urethralis, ischuria vesicalis, ischuria ureterica, and ischuria renalis [2]. At the beginning of the 20th century, acute Bright's disease became the terminology of acute renal failure (ARF), following the extensive pathological study (both of microscopy and macroscopy). During this period, we cannot ignore the major contribution of knowledge by military medicine and traumatic shock to this field. A landmark article was first published in 1941 by Bywaters and Beall during World War II [3]. They reported 4 cases of crush injury followed by impaired of renal function. Besides the description of the natural history of renal injury, they examined the pathology of the kidney and demonstrated widespread tubular damage and pigmented casts inside the tubular lumen. This provided the basic knowledge for subsequent studies that led to the development of the principle of ARF during the

John A. Kellum, MD, FCCM

608, Scaife Hall, Department of Critical Care Medicine

University of Pittsburgh, 3550 Terrace Street

Pittsburgh, PA 15261 (USA)

Tel. +1 412647 7810,Fax +1 412647 8060,E-Mail kellumja@ccm.upmc.edu 


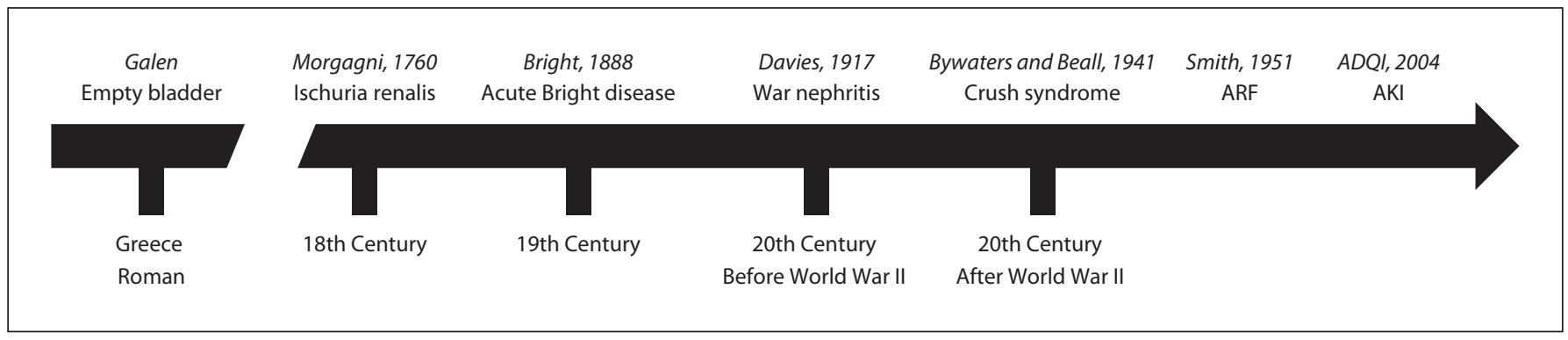

Fig. 1. Historical milestones of AKI.

ensuing decade. Ten years after the report of Bywaters and Beall, Homer W. Smith, introduced the term 'acute renal failure' in a chapter on 'Acute renal failure related to traumatic injuries' in his textbook The Kidney. Structure and Function in Health and Disease [4].

During the 1950s, the knowledge of ARF was greatly increased by three physicians, William J. Kolff who invented artificial kidney [5], John P. Merril who illustrated the clinical course and management of ARF [6], and George E. Schreiner, who described and encouraged the treatment of ARF [7]. However, before 2004 there was no consensus on the diagnostic criteria or clinical definition of ARF resulting in at least 35 definitions in medical literature [8]. This state of various definitions has given rise to a wide range of incidence estimates for ARF from 1 to $25 \%$ of ICU patients and has led to mortality rate estimates of $15-60 \%$ [9-11]. The conventionally used term ARF is often used in reference to the subset of patients, often admitted to the ICU, with a need for acute dialysis support. Evidence from recent studies has demonstrated that even minimal increases in serum creatinine are associated with a dramatic impact on the risk for mortality $[12,13]$. For this reason, the term ARF was replaced by that of AKI, as defined by RIFLE criteria (see below) [14]. $\mathrm{AKI}$ is not just ARF; this term also incorporates the entire spectrum of the syndrome from minor changes in renal function to requirement for renal replacement therapy (RRT). Figure 1 summarizes the historical milestones of AKI.

\section{RIFLE Criteria and AKI Network Staging System}

In 2004, the Acute Dialysis Quality Initiative (ADQI) group developed the RIFLE system through a broad consensus of the experts [14]. The aim of this classification was to standardize the definition of AKI to that achieved by two other common ICU syndromes (sepsis and ARDS). The characteristics of this system are summarized in figure 2. The acronym RIFLE stands for the increasing severity classes Risk, Injury and Failure, and the two outcome classes Loss and End stage kidney disease. The three severity grades are defined on the basis of the changes in serum creatinine or urine output where the worst of each criterion is used. Also, two outcome criteria (loss and end stage kidney disease), are defined by the duration of loss of kidney function, 4 weeks and 3 months, respectively. At present, RIFLE has been validated in more than 550,000 patients around the world, and the original article describing these criteria has been accessed more than 170,000 times [15].

Therefore, it seems that the objective to standardize one of the most common syndromes in ICU has been met. However, concern was initially raised about RIFLE over the use of very small alterations in serum creatinine and urine output; furthermore, some objected to the use of an acronym instead of the numerical stages used in chronic kidney disease. Furthermore, others were concerned that a $50 \%$ increase in serum creatinine was too conservative and sought to demonstrate that even smaller changes were important [12]. In 2007, the AKI network (AKIN), a multi-disciplinary international group, proposed some small modifications to the RIFLE criteria [16]. These modifications can be summarized as follows: (a) broadening of the 'risk' category of RIFLE to include increase in serum creatinine of at least $0.3 \mathrm{mg} / \mathrm{dl}$ even if this does not reach the $50 \%$ threshold; (b) setting a 48 hour window on the first documentation of any criteria; (c) categorizing patients as 'failure' if they are treated with RRT regardless of what their serum creatinine or urine output is at the point of initiation; (d) AKIN also proposed that stages 1,2 and 3 be used instead of R, I and $\mathrm{F}$. 
Fig. 2. Diagram of the RIFLE criteria. Reproduced with permission [14]. sCreat $=$ Serum creatinine concentration; UO = urine output. All serum creatinine references are based on changes from baseline values. The risk criteria include the modifications recommended by AKIN [16].

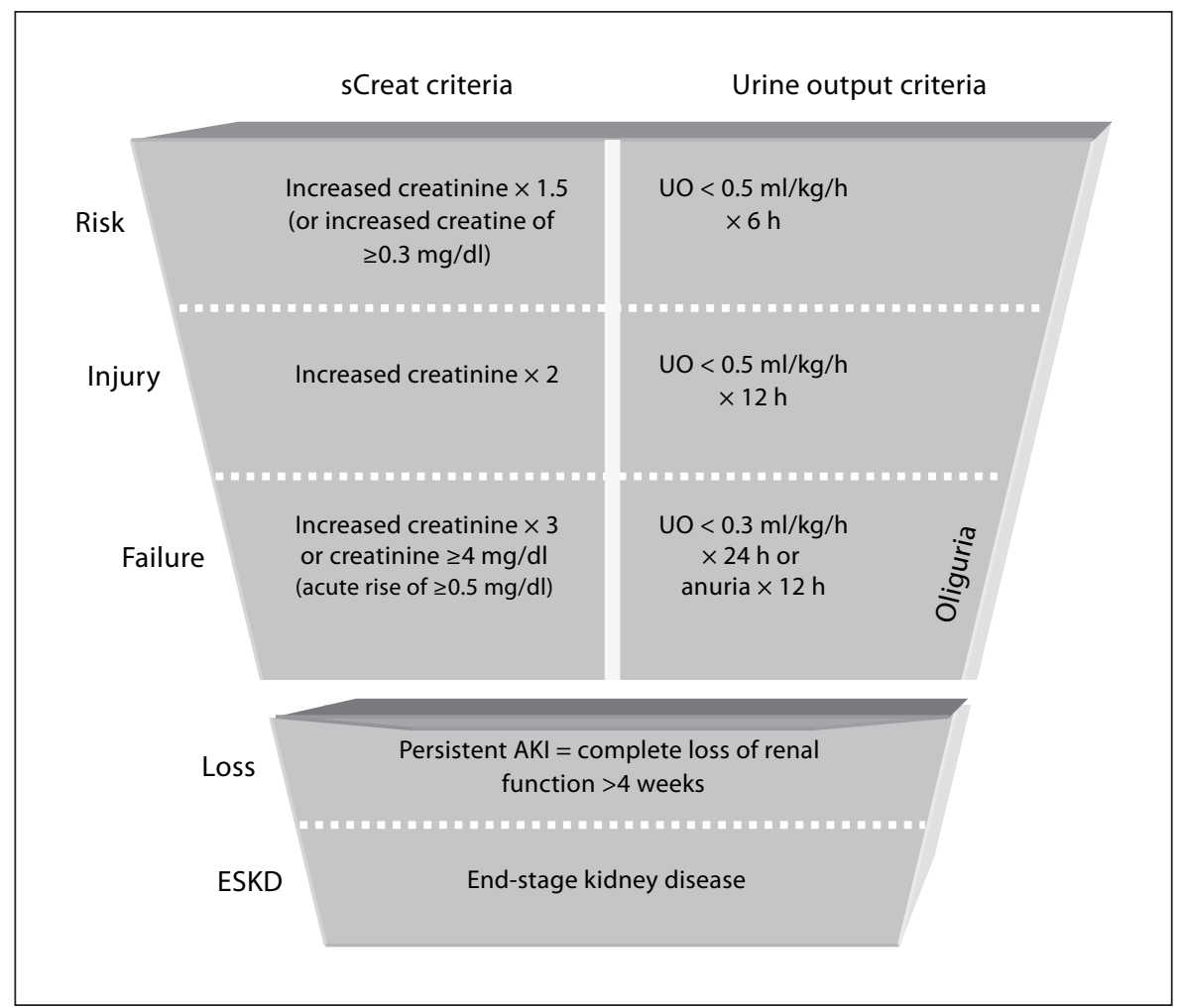

These differences between ADQI-RIFLE and AKIN stages might therefore appear quite modest, but indeed, that was precisely the intent. A recent study by Bagshaw et al. [17] has shown that by broadening the criteria for 'risk' (stage 1) there is increased sensitivity (more individuals are classified as having AKI) - a difference that affects only $1 \%$ of patients. However, the data available to Bagshaw and colleagues were only from day 1 of the ICU stay, and thus the proposed 48-hour time window for reaching at least stage 1 criteria might have excluded patients that should be included in the AKI diagnosis. A subsequent study by Joannidis et al. [18] found that AKIN criteria $(0.3 \mathrm{mg} / \mathrm{dl}$ increase in serum creatinine within a 48 -hour period) identified an additional $9 \%$ of cases not found by RIFLE. Virtually all cases (91\%) were limited to stage 1 . However, use of AKIN criteria alone missed 27\% of cases identified by RIFLE, and these cases included nearly $50 \%$ which developed stage 2 or 3 . We have summarized a series of case examples of how to classify RIFLE criteria and AKIN staging in figure 3. Case 1 is an example of how the AKIN modification can provide for earlier recognition of AKI (day 3 vs. day 5). Furthermore, had creatinine peaked at 1.4, the case would have been 'missed' by the original RIFLE threshold of $50 \%$. How- ever, application of the AKIN criteria requires that creatinine be measured. If for example, creatinine was not measured on days 1 or 2, the diagnosis of AKI could not be made until day 6 . Therefore, when data are limited, using baseline creatinine allows for the diagnosis of AKI earlier. By contrast, case 2 would have been diagnosed and classified the same according to either set of criteria. Case 3 is another example of the limitation of the AKIN criteria. If we restrict to a 48 -hour time window rule, we cannot diagnose AKI by serum creatinine because within no 48-hour time window did the serum creatinine increase by $0.3 \mathrm{mg} / \mathrm{dl}$ or more, even though the serum creatinine increased more than 50\% from baseline. ADQI also included glomerular filtration rate (GFR) in the original RIFLE criteria but with the understanding that it would only be used as a rough 'guide' since few patients will have GFR measured, and a non-steady-state GFR is of limited value in any case. GFR was therefore eliminated in the AKIN modification. Case 4 is the example of using RRT criteria regardless of serum creatinine to classify AKIN staging. Finally, case 5 shows a case of community-acquired AKI where the peak creatinine occurs at (or prior to) admission. Here, the patient can be diagnosed with AKI if the baseline of $1.0 \mathrm{mg} / \mathrm{dl}$ is known or 




Fig. 3. Illustrative cases demonstrating how to diagnose AKI by RIFLE and AKIN staging. In these examples, all patients have baseline serum creatinine of $1.0 \mathrm{mg} / \mathrm{dl}$.

estimated (e.g. using MDRD equation). Note that even if baseline is unavailable, a creatinine of 1.0 on day 6 and after confirms that this is (was) a case of AKI.

Thus, subtle but important differences between AKIN and RIFLE criteria emerge when applied across patients. However, there are several caveats. First, the urine output criteria is the same for both AKIN and RIFLE, and many patients will be diagnosed by this criterion before creatinine changes manifest. Second, in clinical practice, as opposed to retrospective database studies, clinicians are free to obtain additional and more frequent measures of creatinine. Indeed, for high-risk patients, measuring creatinine every 12 or even every $8 \mathrm{~h}$ might be appropriate. It should also be stressed that quantifying and recording urine output is an extremely important and underutilized biomarker of AKI.

Another recommendation from ADQI was how to handle the absence of a baseline serum creatinine. The ADQI group recommended using the MDRD equation to back-estimate a baseline serum creatinine using a low normal value for GFR $\left(75 \mathrm{ml} / \mathrm{min} / \mathrm{m}^{2}\right)$ [14]. This approach was first operationalized by Hoste et al. [19] who used the lowest of the following as the baseline when no baseline was available: hospital admission creatinine; ICU admis- sion creatinine; MDRD estimated creatinine. By using the lowest of these three, the authors ensured that a subject admitted with a low creatinine would have that information included (and thus a higher maximum RIFLE class if the creatinine increased) while a subject admitted with a high creatinine and no history of CKD would be classified based on a change from a theoretical baseline estimated from MDRD.

Given the results of studies comparing RIFLE and AKIN, it would appear that AKIN does not represent an important advance and the original RIFLE criteria provide a more sensitive measure of AKI. Nevertheless, it appears that patients who fulfill AKIN criteria for a 0.3 $\mathrm{mg} / \mathrm{dl}$ increase in serum creatinine within $48 \mathrm{~h}$ but who do not meet RIFLE criteria have clinical syndrome consistent with AKI. These patients are almost exclusively stage 1 patients, and thus including them in the AKI diagnosis would seem appropriate. However, patients who present with an increased creatinine relative to a baseline (measured or estimated) and fulfill RIFLE but not AKIN criteria appear to have a range of severity from stage 1 to 3 and a corresponding mortality. If the clinical context is appropriate (e.g. reliable baseline creatinine), these patients should also be included as having AKI. 


\section{Severity Staging of Patients with AKI}

\section{RIFLE-Risk/AKIN Stage 1}

In some ways, stage $1 \mathrm{AKI}$ may be the most important group, due to the potential of reversibility of this stage. RIFLE criteria may help physicians to be aware of the risk of renal injury and in starting preventive or therapeutic interventions. This might explain why most studies which showed promising results in animal models have failed in clinical trials. In animals, most interventions were started at the beginning or right after AKI was induced, while in clinical studies therapy was started much later. However, due to the relatively small change of serum creatinine in this stratum, it is unclear whether these criteria can detect the difference between functional (transient renal hypoperfusion) and structural (acute tubular necrosis) changes. A recent analysis by Hoste et al. [19] in 5,383 critically ill patients reported that of the $1,510(28 \%)$ patients who were admitted in the risk stage, 840 (56\%) progressed further to more severe RIFLE classes. The other concern for this stage is the inconsistent result of serum creatinine from various methods which are used worldwide [20], and care must be taken not to compare two measurements using two different techniques. As always, clinical judgment is needed. The other parameter in this stratum is urine output, and a reduced output might be the first clue for a decreasing GFR. Until now, we do not have much evidence validating the use of urine output for determining the severity of AKI compared with serum creatinine. Obstacles which limit the use this parameter are that it is time consuming, influenced by diuretics, and will fail to detect non-oliguric AKI. However, the amount of urine output (less than $100 \mathrm{ml}$ during the first $8 \mathrm{~h}$ after bypass surgery) was implicated as the criteria to start early RRT in recent two studies [21, 22]. Patients who began early RRT showed a better outcome compared to the patients who started under more conventional criteria.

\section{RIFLE-Injury/AKIN Stage 2}

At this stage of AKI, the likelihood that the changes in serum creatinine or urine output are purely functional (i.e. prerenal) becomes smaller. From the study by Hoste et al. [19] in 5,383 ICU patients, it is this stage that is first independently associated with hospital survival after controlling for baseline severity of illness and underlying comorbidity and age. Furthermore, this study demonstrated that more than one third (36.8\%) of the patients with stage 2 proceeded to stage 3 [19]. Besides clinical evaluation and basic urine analysis, detection of loss of urine-concentrating ability by using urine osmolality and fraction excretion of filtered sodium $\left(\mathrm{FE}_{\mathrm{Na}}\right)$ is accepted as one of the parameters to discriminate between prerenal physiology and renal injury. However, these parameters have important limitations. First, a paradoxically high $\mathrm{FE}_{\mathrm{Na}}$ despite the presence of prerenal azotemia occurs during diuretic therapy, including mannitol. Also, the prerenal state in chronic kidney disease may result in a high $\mathrm{FE}_{\mathrm{Na}}$ due to chronic adaptation to increased 'single-nephron GFR'. On the other hand, a low $\mathrm{FE}_{\mathrm{Na}}$ does not always indicate decreased renal blood flow and can also be observed in the early stage of obstruction, acute glomerulonephritis, myoblobinuric renal failure and contrast-induced nephropathy as well as in patients with sepsis-induced AKI. Sepsis also appears to result in changes in urine chemistries which do not follow conventional patterns.

\section{RIFLE-Failure/AKIN Stage 3}

At this end of the spectrum, renal function has markedly dropped, and RRT becomes an important consideration. So-called 'conventional' indications for initiation of RRT in AKI include volume overload, hyperkalemia, metabolic acidosis, and overt uremic symptoms. Although lacking specific evidence, most experts consider the indication of starting RRT to be expanded to providing 'supporting therapy'. This evolving view is supported by evidence that patients reaching RIFLE-F and not undergoing RRT still have high hospital mortality [19]. There is also the belief that early RRT can decrease morbidity and mortality. Only $14.2 \%$ of ICU patient reaching 'F' criteria received RRT in one recent study [19]. Such evidence demands that we change the way we think about this disorder. Is renal support underutilized or delayed?

\section{Loss and End-Stage Kidney Disease}

Long-term outcomes after AKI have become an area of intense research in the field of AKI, including how an episode of AKI affects risk of development and/or progression of chronic kidney disease. A recent study by Uchino et al. [11] demonstrated that $13.8 \%$ of AKI patients remained dialysis dependent at the time of hospital discharge. However, research in this area is still very much in its infancy. Results from the recent Acute Renal Failure Trials Network study showed that full recovery was achieved in less than $50 \%$ of survivors of AKI requiring RRT [23]. 


\section{Epidemiology of AKI}

Since the first publication of RIFLE criteria in 2004, there have been more than 50 articles examining the epidemiology of AKI using the RIFLE criteria [24]. Moreover, most studies in the field of AKI have also used the RIFLE criteria to define the disorder [25]. The incidence and outcome of AKI have varied according to population (ICU, non-ICU, and population based), parameters used for the criteria (just serum creatinine vs. both creatinine and urine output), acquisition of baseline creatinine, and timing of endpoint (in hospital mortality, 30, 60 days, or 6 months).

In the study by Hoste et al. [19] in 5,383 critically ill patients in seven ICUs, AKI occurred in $67 \%$ of patients, with $12 \%$ achieving a maximum class of $\mathrm{R}, 27 \%$ I and $28 \%$ F. Patients with a maximum score of $\mathrm{R}$ had a mortality rate of $8.8 \%$, compared to $11.4 \%$ for I and $26.3 \%$ for F. Patients who had no evidence of AKI had a mortality rate of 5.5\%. Furthermore, RIFLE-I (hazard ratio of 1.4) and RIFLE-F (hazard ratio of 2.7) were independent predictors of hospital mortality after adjusting for other variables known to predict outcome in critically ill patients.

Uchino et al. [26] focused on the predictive ability of the RIFLE classification in a cohort of 20,126 patients admitted to a teaching hospital for $>24$ h over a 3-year period. The authors used serum creatinine from an electronic laboratory database to classify patients into RIFLE-R, I and F and followed them to hospital discharge or death. Nearly $10 \%$ of patients achieved a maximum RIFLE-R, 5\% I and 3.5\% F. There was a nearly linear increase in hospital mortality with increasing RIFLE class with patients at $\mathrm{R}$ having more than 3 times the mortality rate of patients without AKI. In multivariate regression, class R carried an odds ratio of hospital mortality of 2.5, I of 5.4 and $\mathrm{F}$ of 10.1 .

NEiPHROS-AKI was the first prospective multicenter study that demonstrated the incidence of AKI in 19 ICUs in the three regions in northeastern Italy during a 3month period [27]. Of 2,164 ICU patients, 234 (10.8\%) developed AKI, 19\% R, 35\% I, and 46\% F. Overall mortality was highest among those in F criteria (mortality: $20 \%$ $\mathrm{R}, 29.3 \% \mathrm{I}$, and $49.5 \% \mathrm{~F}$ ). The odds ratio for mortality based on RIFLE-F criteria was significantly higher than that based on R criteria $(4.88,95 \%$ CI $1.40-17.07$, $p$ value 0.013 ).

In the first population-based study of AKI, Ali et al. [28] studied the incidence of AKI in Northern Scotland, a geographical population base of 523,390 . The incidence of AKI was 1,811 per million population. Sepsis was a precipitating factor in $47 \%$ of patients. RIFLE classification was useful for predicting recovery of renal function ( $p<0.001$ ), requirement for RRT ( $p<0.001$ ), length of hospital stay for survivors $(\mathrm{p}<0.001)$, and in-hospital mortality $(\mathrm{p}=0.035)$.

Ostermann and Chang [29] retrospectively analyzed database of 41,972 patients admitted to 22 ICUs in the UK and Germany between 1989 and 1999 as part of the Riyadh Intensive Care Program database. AKI defined by RIFLE (creatinine only) occurred in 15,019 (35.8\%) patients: 7,207 (17.2\%) with R, 4,613 (11\%) I, and 3,199 (7.6\%) F. Hospital mortality rates were RIFLE-R 20.9\%, I $45.6 \%$, and $\mathrm{F} 56.8 \%$, compared with $8.4 \%$ among patients without AKI.

Bagshaw et al. [17] studied 120,123 patients admitted to 57 ICUs across Australia for at least $24 \mathrm{~h}$ from January 2000 to December 2005. They also examined AKI by RIFLE using only creatinine and only on ICU admission. In striking similarity to the study by Ostermann, AKI occurred in $36.1 \%$, with a maximum category $\mathrm{R}$ in $16.3 \%$, I in $13.6 \%$, and $\mathrm{F}$ in $6.3 \%$. AKI, defined by any RIFLE category, was associated with an increase in hospital mortality (OR 3.29, 95\% CI 3.19-3.41, p < 0.0001). The crude hospital mortality by RIFLE category was $17.9 \%$ for R, $27.7 \%$ for I and 33.2\% for F. By multivariable analysis, each RIFLE category was independently associated with hospital mortality (OR: R 1.58, I 2.54 and F 3.22).

In the largest study to date, Thakar et al. [30] reported 323,395 patients admitted to one of 191 Veteran Affairs ICUs across USA. By using AKIN criteria (creatinine only and only in patients with multiple serum creatinine measures), overall AKI incidence was $22 \%$ (71,486 patients), $17.5 \%$ with stage $1,2.4 \%$ with stage 2 , and $2 \%$ with stage 3. After adjusting for severity of illness, odds of death increased with increasing severity of AKI, stage 1: $2.2(2.17-2.30)$, stage 2: 6.1 (5.74-6.44), and stage 3: 8.6 (8.07-9.15). Gender is an additional limitation of this study since $98 \%$ of the population was male.

Finally, Joannidis et al. [18] studied 16,784 patients admitted to one of 330 ICUs across Austria. By testing AKIN criteria (using $\mathrm{Cr}$ on day of ICU admission as baseline $\mathrm{Cr}$ ) and RIFLE criteria (using Cr from MDRD formula as baseline Cr), overall AKI incidence was 28.5 and $35.5 \%$, respectively. Odds ratios for hospital mortality based on AKIN staging by logistic regression were as follows: stage 1: 2.07 (1.77-2.43), stage 2: 1.93 (2.64-3.38), and stage 3: 2.99 (2.64-3.38), while odds ratios of RIFLE criteria by using logistic regression were as follows: R 1.38 (1.17- 
Table 1. Summary of the epidemiologic studies of AKI (including only studies with more than 1,000 patients)

\begin{tabular}{|c|c|c|c|c|c|c|c|c|c|c|}
\hline \multirow{2}{*}{$\begin{array}{l}\text { Reference and } \\
\text { year }\end{array}$} & \multirow[t]{2}{*}{ Patients } & \multirow{2}{*}{$\begin{array}{l}\text { Population } \\
\text { studied }\end{array}$} & \multirow{2}{*}{$\begin{array}{l}\text { Type of } \\
\text { study }\end{array}$} & \multirow{2}{*}{$\begin{array}{l}\text { Single/ } \\
\text { multicenter }\end{array}$} & \multirow{2}{*}{$\begin{array}{l}\text { Criteria used } \\
\text { for RIFLE }\end{array}$} & \multirow{2}{*}{$\begin{array}{l}\text { AKI } \\
\text { incidence } \\
\text { (by RIFLE) }\end{array}$} & \multirow{2}{*}{$\begin{array}{l}\text { Time of } \\
\text { end point }\end{array}$} & \multicolumn{3}{|c|}{ Mortality } \\
\hline & & & & & & & & $\%$ & $\begin{array}{l}\text { HR } \\
(95 \% \text { CI })\end{array}$ & $\begin{array}{l}\mathrm{p} \\
\text { value }\end{array}$ \\
\hline $\begin{array}{l}\text { Hoste et al. } \\
2006[19]\end{array}$ & 5,383 & ICU & retrospective & single & $\mathrm{Cr}, \mathrm{UO}$ & $67.2 \%$ & in hospital & $\begin{array}{l}\text { R: } 8.8 \\
\text { I: } 11.4 \\
\text { F: } 26.3\end{array}$ & $\begin{array}{l}1 \\
1.4(1.02-1.88) \\
2.7(2.03-3.55)\end{array}$ & $\begin{array}{r}0.037 \\
<0.001\end{array}$ \\
\hline $\begin{array}{l}\text { Uchino et al. } \\
2006 \text { [26] }\end{array}$ & 20,126 & ICU & retrospective & multicenter & Cr, GFR & $18.0 \%$ & 30 days & $\begin{array}{l}\mathrm{N}: 4.4 \\
\mathrm{R}: 15.1 \\
\mathrm{I}: 29.2 \\
\text { F: } 41.1\end{array}$ & $\begin{array}{l}1 \\
2.5(2.15-2.99) \\
5.4(4.55-6.44) \\
10.1(8.32-12.32)\end{array}$ & $\begin{array}{l}<0.001 \\
<0.001 \\
<0.001\end{array}$ \\
\hline $\begin{array}{l}\text { Cruz et al. } \\
2007 \text { [27] }\end{array}$ & 2,164 & ICU & prospective & multicenter & $\mathrm{Cr}, \mathrm{UO}$ & $10.8 \%$ & 60 days & $\begin{array}{l}\text { R: } 20 \\
\text { I: } 29.3 \\
\text { F: } 49.5\end{array}$ & $\begin{array}{l}1 \\
2.2(0.84-6.02) \\
4.9(1.40-17.07)\end{array}$ & $\begin{array}{l}0.11 \\
0.01\end{array}$ \\
\hline $\begin{array}{l}\text { Ali et al. } \\
2007 \text { [28] }\end{array}$ & 5,321 & $\begin{array}{l}\text { population } \\
\text { based }\end{array}$ & retrospective & multicenter & $\mathrm{Cr}, \mathrm{GFR}$ & $1,811 \mathrm{pmp}$ & 6 months & $\begin{array}{l}\text { R: } 46 \\
\text { I: } 48 \\
\text { F: } 56\end{array}$ & NA & 0.22 \\
\hline $\begin{array}{l}\text { Ostermann et al. } \\
2007 \text { [29] }\end{array}$ & 41,972 & ICU & retrospective & multicenter & $\mathrm{Cr}, \mathrm{GFR}$ & $35.8 \%$ & in hospital & $\begin{array}{l}\text { N: } 8.4 \\
\text { R: } 20.9 \\
\text { I: } 45.6 \\
\text { F: } 56.8\end{array}$ & $\begin{array}{l}1 \\
1.4(1.28-1.53) \\
1.96(1.80-2.14) \\
1.59(1.43-1.76)\end{array}$ & $\begin{array}{l}<0.001 \\
<0.001 \\
<0.001\end{array}$ \\
\hline $\begin{array}{l}\text { Bagshaw et al. } \\
2008 \text { [17] }\end{array}$ & 120,123 & ICU & retrospective & multicenter & $\mathrm{Cr}, \mathrm{UO}$ & $36.1 \%$ & in hospital & $\begin{array}{l}\text { N: } 8.9 \\
\text { R: } 17.9 \\
\text { I: } 27.7 \\
\text { F: } 33.2\end{array}$ & $\begin{array}{l}1 \\
2.24(2.1-2.3) \\
3.95(3.8-4.1) \\
5.13(4.9-5.4)\end{array}$ & $\begin{array}{l}<0.001 \\
<0.001 \\
<0.001\end{array}$ \\
\hline $\begin{array}{l}\text { Thakar et al. } \\
2009 \text { [30] }\end{array}$ & 325,395 & ICU & retrospective & multicenter & $\mathrm{Cr}$ & $22 \%$ & in hospital & NA & $\begin{array}{l}2.2(2.17-2.3) \\
6.1(5.77-6.44) \\
8.6(8.07-9.15)\end{array}$ & NA \\
\hline $\begin{array}{l}\text { Joannidis et al. } \\
2009 \text { [18] }\end{array}$ & 16,784 & ICU & retrospective & multicenter & $\mathrm{Cr}, \mathrm{UO}$ & $35.5 \%$ & in hospital & $\begin{array}{l}\text { N: } 13.6 \\
\text { R: } 29.2 \\
\text { I: } 32.2 \\
\text { F: } 42.6\end{array}$ & $\begin{array}{l}1 \\
1.38(1.17-1.63) \\
1.90(1.65-2.18) \\
2.99(2.66-3.36)\end{array}$ & $\begin{array}{r}0.001 \\
<0.001 \\
<0.001\end{array}$ \\
\hline
\end{tabular}

$\mathrm{UO}=$ Urine output; $\mathrm{HR}=$ hazard ratio; $\mathrm{pmp}=$ per million population; $\mathrm{N}=$ no $\mathrm{AKI} ; \mathrm{R}=$ risk; $\mathrm{I}=$ injury; $\mathrm{F}=$ failure; $\mathrm{NA}=$ not available.

1.63), I 1.90 (1.65-2.18), F 2.99 (2.66-3.36). Thus, limitations in various studies (lack of urine output, baseline creatinine, or complete data on all patients) make incidence estimates uncertain. However, a consistent result is that survival is significantly reduced as AKI occurs and as severity of AKI increases. Table 1 summarizes the epidemiologic studies of AKI.

\section{Conclusions}

This article has reviewed the recent information about the definition, classification, and epidemiology of AKI. RIFLE criteria afford a great opportunity for AKI researchers in aspects such as comparing the incidence of
AKI, early diagnosed AKI, interventional studies to prevent development or facilitate the recovery process of AKI, and predict outcome of AKI. Many potential serum or urine biomarkers of tubular injury are undergoing extensive investigation and should be available in the near future. This will play an important part in improving AKI detection and staging. However, even with the development of injury markers, the 'tried and true' markers of serum creatinine and urine output disciplined by current criteria will be important components of the definition and classification of AKI. 


\section{References}

$\checkmark 1$ Eknoyan G: The origins of nephrology - Galen, the founding father of experimental renal physiology. Am J Nephrol 1989;9:66-82.

$\checkmark 2$ Eknoyan G: Emergence of the concept of acute renal failure. Am J Nephrol 2002;22: 225-230.

$\checkmark 3$ Bywaters EGL, Beall D: Crush injuries and renal function. BMJ 1941;i:427-432.

4 Smith HW: The Kidney. Structure and Function in Health and Disease. New York, Oxford University Press, 1951.

5 Cameron JS: History of the Treatment of Renal Failure by Dialysis. New York, Oxford University Press, 2002, p 118.

$\checkmark 6$ Swann RC, Merrill JP: The clinical course of acute renal failure. Medicine (Baltimore) 1953;32:215-292.

$\checkmark 7$ Schreiner GE: Acute renal failure: the dawn of dialysis and the roaring 50s. Nephrol Dial Transplant 1994;9(suppl 4):1-8.

$>8$ Kellum JA, Levin N, Bouman C, Lameire N: Developing a consensus classification system for acute renal failure. Curr Opin Crit Care 2002;8:509-514.

$>9$ Liaño F, Pascual J: Epidemiology of acute renal failure: a prospective, multicenter, community-based study. Madrid Acute Renal Failure Study Group. Kidney Int 1996;50: 811-818.

10 Brivet FG, Kleinknecht DJ, Loirat P, Landais PJ: Acute renal failure in intensive care units - causes, outcome, and prognostic factors of hospital mortality; a prospective, multicenter study. French Study Group on Acute Renal Failure. Crit Care Med 1996;24: 192-198.

-11 Uchino S, Kellum JA, Bellomo R, Doig GS, Morimatsu H, Morgera S, Schetz M, Tan I, Bouman C, Macedo E, Gibney N, Tolwani A, Ronco C, Beginning and Ending Supportive Therapy for the Kidney (BEST Kidney) Investigators. Acute renal failure in critically ill patients: a multinational, multicenter study. JAMA 2005;294:813-818.

$\checkmark 12$ Chertow GM, Burdick E, Honour M, Bonventre JV, Bates DW: Acute kidney injury, mortality, length of stay, and costs in hospitalized patients. J Am Soc Nephrol 2005;16: 3365-3370.
13 Lassnigg A, Schmidlin D, Mouhieddine M, Bachmann LM, Druml W, Bauer P, Hiesmayr M: Minimal changes of serum creatinine predict prognosis in patients after cardiothoracic surgery: a prospective cohort study. J Am Soc Nephrol 2004;15:15971660 .

14 Bellomo R, Ronco C, Kellum JA, Mehta RL, Palevsky P, Acute Dialysis Quality Initiative workgroup. Acute renal failure - definition, outcome measures, animal models, fluid therapy and information technology needs: the Second International Consensus Conference of the Acute Dialysis Quality Initiative (ADQI) Group. Crit Care 2004;8:R204R212.

15 http://ccfrorum.com/mostviewedalltime 04_23_2009.

16 Mehta RL, Kellum JA, Shah SV, Molitoris BA, Ronco C, Warnock DG, et al: Acute Kidney Injury Network. Acute Kidney Injury Network: report of an initiative to improve outcomes in acute kidney injury. Crit Care 2007;11:R31.

-17 Bagshaw SM, George C, Bellomo R, ANZICS Database Management Committe: A comparison of the RIFLE and AKIN criteria for acute kidney injury in critically ill patients. Nephrol Dial Transplant 2008;23:15691574.

18 Joannidis M, Metnitz B, Bauer P, Schusterschitz N, Moreno R, Druml W, Metnitz PG: Acute kidney injury in critically ill patients classified by AKIN versus RIFLE using the SAPS 3 database. Intensive Care Med 2009; 35:1692-1702.

19 Hoste EA, Clermont G, Kersten A, Venkataraman R, Angus DC, De Bacquer D, et al: RIFLE criteria for acute kidney injury are associated with hospital mortality in critically ill patients: a cohort analysis. Crit Care 2006; 10:R73.

20 Van Biesen W, Vanholder R, Veys N, Verbeke F, Delanghe J, De Bacquer D, et al: The importance of standardization of creatinine in the implementation of guidelines and recommendations for CKD: implications for CKD management programmes. Nephrol Dial Transplant 2006;21:77-83.
21 Demirkiliç U, Kuralay E, Yenicesu M, Cağlar $\mathrm{K}, \mathrm{Oz}$ BS, Cingöz F, Günay C, Yildirim V, Ceylan S, Arslan M, Vural A, Tatar H: Timing of replacement therapy for acute renal failure after cardiac surgery. J Card Surg 2004;19:17-20.

$\checkmark 22$ Elahi MM, Lim MY, Joseph RN, Dhannapuneni RR, Spyt TJ: Early hemofiltration improves survival in post-cardiotomy patients with acute renal failure. Eur J Cardiothorac Surg 2004;26:1027-1031.

23 Palevsky PM, Zhang JH, O’Connor TZ, et al: Intensity of renal support in critically ill patients with acute kidney injury. N Engl J Med 2008;359:7-20.

24 Ricci Z, Cruz D, Ronco C: The RIFLE criteria and mortality in acute kidney injury: a systematic review. Kidney Int 2008;73:538546 .

25 Hoste EA, Schurgers M: Epidemiology of acute kidney injury: how big is the problem? Crit Care Med 2008;36(suppl 4):S146-S151.

$>26$ Uchino S, Bellomo R, Goldsmith D, Bates S, Ronco C: An assessment of the RIFLE criteria for acute renal failure in hospitalized patients. Crit Care Med 2006;34:1913-1917.

27 Cruz DN, Bolgan I, Perazella MA, Bonello M, de Cal M, Corradi V, et al: North East Italian Prospective Hospital Renal Outcome Survey on Acute Kidney Injury (NEiPHROS-AKI) Investigators. North East Italian Prospective Hospital Renal Outcome Survey on Acute Kidney Injury (NEiPHROS-AKI): targeting the problem with the RIFLE Criteria. Clin J Am Soc Nephrol 2007;2:418-425.

28 Ali T, Khan I, Simpson W, Prescott G, Townend J, Smith W, et al: Incidence and outcomes in acute kidney injury: a comprehensive population-based study. J Am Soc Nephrol 2007; 18:1292-1298.

29 Ostermann M, Chang RW: Acute kidney injury in the intensive care unit according to RIFLE. Crit Care Med 2007;35:1837-1843.

30 Thakar CV, Christianson A, Freyberg R, Almenoff P, Render ML: Incidence and outcomes of acute kidney injury in intensive care units: a Veterans Administration study. Crit Care Med 2009;37:2552-2558. 